ISSN 2078-3744. Вісник Львів. ун-ту. Серія мех.-мат. 2020. Випуск 90. С. 48-56

Visnyk of the Lviv Univ. Series Mech. Math. 2020. Issue 90. P. 48-56

http://publications.lnu.edu.ua/bulletins/index.php/mmf

doi: http://dx.doi.org/10.30970/vmm.2020.90.048-056

УДК 512.536

\title{
ON FEEBLY COMPACT TOPOLOGIES ON THE SEMIGROUP $B_{\omega}^{\mathscr{F}_{1}}$
}

\section{Oleksandra LYSETSKA}

Ivan Franko National University of Lviv, Universytetska Str., 1, 79000, Lviv, Ukraine

e-mail: o.yu.sobol@gmail.com

We study the Gutik-Mykhalenych semigroup $\boldsymbol{B}_{\omega}^{\mathscr{F}_{1}}$ in the case when the family $\mathscr{F}_{1}$ consists of the empty set and all singleton in $\omega$. We show that $\boldsymbol{B}_{\omega}^{\mathscr{F}_{1}}$ is isomorphic to subsemigroup $\mathscr{B}_{\omega}^{\rightleftarrows}\left(\omega_{\text {min }}\right)$ of the Brandt $\omega$-extension of the semilattice $(\omega, \mathrm{min})$ and describe all shift-continuous feebly compact $T_{1}$ topologies on the semigroup $\mathscr{B}_{\omega}^{\rightleftarrows}\left(\omega_{\text {min }}\right)$. In particular, we prove that every shiftcontinuous feebly compact $T_{1}$-topology $\tau$ on $\boldsymbol{B}_{\omega}^{\mathscr{F} 1}$ is compact and moreover in this case the space $\left(\boldsymbol{B}_{\omega}^{\mathscr{F}_{1}}, \tau\right)$ is homeomorphic to the one-point Alexandroff compactification of the discrete countable space $\mathfrak{D}(\omega)$.

Key words: semitopological semigroup, feebly compact, compact, Brandt $\omega$-extension.

We shall follow the terminology of [4, 5, 6, 7, 27, By $\omega$ we denote the first infinite cardinal.

A semigroup $S$ is called inverse if for any element $x \in S$ there exists a unique $x^{-1} \in S$ such that $x x^{-1} x=x$ and $x^{-1} x x^{-1}=x^{-1}$. The element $x^{-1}$ is called the inverse of $x \in S$. If $S$ is an inverse semigroup, then the function inv: $S \rightarrow S$ which assigns to every element $x$ of $S$ its inverse element $x^{-1}$ is called the inversion.

If $S$ is a semigroup, then we shall denote the subset of all idempotents in $S$ by $E(S)$. If $S$ is an inverse semigroup, then $E(S)$ is closed under multiplication and we shall refer to $E(S)$ as a band (or the band of $S$ ). Then the semigroup operation on $S$ determines the following partial order $\preccurlyeq$ on $E(S): e \preccurlyeq f$ if and only if $e f=f e=e$. This order is called the natural partial order on $E(S)$. A semilattice is a commutative semigroup of idempotents.

If $S$ is an inverse semigroup then the semigroup operation on $S$ determines the following partial order $\preccurlyeq$ on $S: s \preccurlyeq t$ if and only if there exists $e \in E(S)$ such that $s=t e$. This order is called the natural partial order on $S[28$.

2020 Mathematics Subject Classification: 22A15, 20A15, 54D10, 54D30, 54H12

(C) Lysetska, O., 2020 
The bicyclic monoid $\mathscr{C}(p, q)$ is the semigroup with the identity 1 generated by two elements $p$ and $q$ subjected only to the condition $p q=1$. The semigroup operation on $\mathscr{C}(p, q)$ is defined as follows:

$$
q^{k} p^{l} \cdot q^{m} p^{n}=q^{k+m-\min \{l, m\}} p^{l+n-\min \{l, m\}} .
$$

It is well known that the bicyclic monoid $\mathscr{C}(p, q)$ is a bisimple (and hence simple) combinatorial $E$-unitary inverse semigroup and every non-trivial congruence on $\mathscr{C}(p, q)$ is a group congruence [5].

A topological (semitopological) semigroup is a topological space together with a continuous (separately continuous) semigroup operation. If $S$ is a semigroup and $\tau$ is a topology on $S$ such that $(S, \tau)$ is a topological semigroup, then we shall call $\tau$ a semigroup topology on $S$, and if $\tau$ is a topology on $S$ such that $(S, \tau)$ is a semitopological semigroup, then we shall call $\tau$ a shift-continuous topology on $S$.

Next we shall describe the construction which is introduced by Gutik and Mykhalenych in [10].

Let $\mathscr{P}(\omega)$ be the family of all subsets of $\omega$. For any $F \in \mathscr{P}(\omega)$ and $n, m \in \omega$ we put $n-m+F=\{n-m+k: k \in F\}$ if $F \neq \varnothing$ and $n-m+F=\varnothing$ otherwise. A subfamily $\mathscr{F} \subseteq \mathscr{P}(\omega)$ is called $\omega$-closed if $F_{1} \cap\left(-n+F_{2}\right) \in \mathscr{F}$ for all $n \in \omega$ and $F_{1}, F_{2} \in \mathscr{F}$.

Let $\boldsymbol{B}_{\omega}$ be the bicyclic monoid and $\mathscr{F}$ be an $\omega$-closed subfamily of $\mathscr{P}(\omega)$. On the set $\boldsymbol{B}_{\omega} \times \mathscr{F}$ we define the semigroup operation "." in the following way

$$
\left(i_{1}, j_{1}, F_{1}\right) \cdot\left(i_{2}, j_{2}, F_{2}\right)= \begin{cases}\left(i_{1}-j_{1}+i_{2}, j_{2},\left(j_{1}-i_{2}+F_{1}\right) \cap F_{2}\right), & \text { if } j_{1} \leqslant i_{2} \\ \left(i_{1}, j_{1}-i_{2}+j_{2}, F_{1} \cap\left(i_{2}-j_{1}+F_{2}\right)\right), & \text { if } j_{1} \geqslant i_{2}\end{cases}
$$

In [10] it is proved that if the family $\mathscr{F} \subseteq \mathscr{P}(\omega)$ is $\omega$-closed then $\left(\boldsymbol{B}_{\omega} \times \mathscr{F}, \cdot\right)$ is a semigroup. Moreover, if an $\omega$-closed family $\mathscr{F} \subseteq \mathscr{P}(\omega)$ contains the empty set $\varnothing$ then the set $\boldsymbol{I}=\{(i, j, \varnothing): i, j \in \omega\}$ is an ideal of the semigroup $\left(\boldsymbol{B}_{\omega} \times \mathscr{F}, \cdot\right)$. For any $\omega$-closed family $\mathscr{F} \subseteq \mathscr{P}(\omega)$ the semigroup

$$
\boldsymbol{B}_{\omega}^{\mathscr{F}}= \begin{cases}\left(\boldsymbol{B}_{\omega} \times \mathscr{F}, \cdot\right) / \boldsymbol{I}, & \text { if } \varnothing \in \mathscr{F} \\ \left(\boldsymbol{B}_{\omega} \times \mathscr{F}, \cdot\right), & \text { if } \varnothing \notin \mathscr{F}\end{cases}
$$

is defined in [10]. The semigroup $\boldsymbol{B}_{\omega}^{\mathscr{F}}$ generalizes the bicyclic monoid and the countable semigroup of matrix units. It is proven in [10] that $\boldsymbol{B}_{\omega}^{\mathscr{F}}$ is combinatorial inverse semigroup and Green's relations, the natural partial order on $\boldsymbol{B}_{\omega}^{\mathscr{F}}$ and its set of idempotents are described. The criteria of simplicity, 0-simplicity, bisimplicity, 0-bisimplicity of the semigroup $\boldsymbol{B}_{\omega}^{\mathscr{F}}$ and when $\boldsymbol{B}_{\omega}^{\mathscr{F}}$ has the identity, is isomorphic to the bicyclic semigroup or the countable semigroup of matrix units are given. In particular, in [10] it is proved that the semigroup $\boldsymbol{B}_{\omega}^{\mathscr{F}}$ is isomorphic to the semigrpoup of $\omega \times \omega$-matrix units if and only if $\mathscr{F}$ consists of a sigleton and the empty set.

We define

$$
\mathscr{F}_{1}=\{A \subseteq \omega:|A| \leqslant 1\} .
$$

It is obvious that $\mathscr{F}_{1}$ is an $\omega$-closed subfamily of $\mathscr{P}(\omega)$ and hence $\boldsymbol{B}_{\omega}^{\mathscr{F}_{1}}$ is an inverse semigroup with zero. Later by $(i, j,\{k\})$ we denote a non-zero element of $\boldsymbol{B}_{\omega}^{\mathscr{F}_{1}}$ for some $i, j, k \in \omega$ and by $\mathbf{0}$ the zero of $\boldsymbol{B}_{\omega}^{\mathscr{F}_{1}}$. 
In this paper we study properties of the semigroup $\boldsymbol{B}_{\omega}^{\mathscr{F}_{1}}$. We show that $\boldsymbol{B}_{\omega}^{\mathscr{F}_{1}}$ is isomorphic to the subsemigroup $\mathscr{B}_{\omega}^{\rightleftarrows}\left(\omega_{\min }\right)$ of the Brandt $\omega$-extension of the semilattice $(\omega, \min )$ and describe all shift-continuous feebly compact $T_{1}$-topologies on the semigroup $\mathscr{B}_{\omega}^{\longmapsto}\left(\omega_{\text {min }}\right)$. In particular, we prove that every shift-continuous feebly compact $T_{1^{-}}$

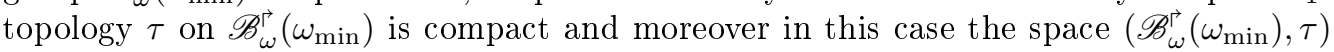
is homeomorphic to the one-point Alexandroff compactification of the discrete countable space $\mathfrak{D}(\omega)$.

Proposition 2 of [10] implies Proposition 1 which describes the natural partial order on $\boldsymbol{B}_{\omega}^{\mathscr{F}_{1}}$.

Proposition 1. Let $\left(i_{1}, j_{1},\left\{k_{1}\right\}\right)$ and $\left(i_{2}, j_{2},\left\{k_{2}\right\}\right)$ be non-zero elements of the semigroup $\boldsymbol{B}_{\omega}^{\mathscr{F}_{1}}$. Then $\left(i_{1}, j_{1},\left\{k_{1}\right\}\right) \preccurlyeq\left(i_{2}, j_{2},\left\{k_{2}\right\}\right)$ if and only if

$$
k_{2}-k_{1}=i_{1}-i_{2}=j_{1}-j_{2}=p
$$

for some $p \in \omega$.

Proposition 1 implies the structure of maximal chains in $\boldsymbol{B}_{\omega}^{\mathscr{F}_{1}}$ with the respect to its natural partial order

Corollary 1. Let $i, j$ be arbitrary elements of $\omega$. Then the following finite series

$$
\begin{aligned}
& \mathbf{0} \preccurlyeq(i, j,\{0\}) ; \\
& \mathbf{0} \preccurlyeq(i+1, j+1,\{0\}) \preccurlyeq(i, j,\{1\}) ; \\
& \mathbf{0} \preccurlyeq(i+2, j+2,\{0\}) \preccurlyeq(i+1, j+1,\{1\}) \preccurlyeq(i, j,\{2\}) ; \\
& \quad \ldots \quad \cdots \quad \cdots \quad \cdots \quad \cdots \quad \cdots \quad \cdots \\
& \mathbf{0} \preccurlyeq(i+k, j+k,\{0\}) \preccurlyeq(i+k-1, j+k-1,\{1\}) \preccurlyeq \cdots \preccurlyeq(i, j,\{k\}) ;
\end{aligned}
$$

describes maximal chains in the semigroup $\boldsymbol{B}_{\omega}^{\mathscr{F}_{1}}$.

We need the following construction from 8 .

Let $S$ be a semigroup with zero and $\lambda \geqslant 1$ be a cardinal. On the set $B_{\lambda}(S)=$ $(\lambda \times S \times \lambda) \sqcup\{\mathscr{O}\}$ we define a semigroup operation as follows

$$
(\alpha, s, \beta) \cdot(\gamma, t, \delta)=\left\{\begin{array}{cl}
(\alpha, s t, \delta), & \text { if } \beta=\gamma \\
\mathscr{O}, & \text { if } \beta \neq \gamma
\end{array}\right.
$$

and $(\alpha, s, \beta) \cdot \mathscr{O}=\mathscr{O} \cdot(\alpha, s, \beta)=\mathscr{O} \cdot \mathscr{O}=\mathscr{O}$, for all $\alpha, \beta, \gamma, \delta \in \lambda$ and $s, t \in S$. If $S$ is a monoid then the semigroup $\mathscr{B}_{\lambda}(S)$ is called the Brandt $\lambda$-extension of the semigroup $S$ [8]. Algebraic properties of $\mathscr{B}_{\lambda}(S)$ and its generalization Brandt $\lambda^{0}$-extensions $\mathscr{B}_{\lambda}^{0}(S)$ of semigroups are studied in [8, 13]. The structures, topologizations of the semigroups $\mathscr{B}_{\lambda}(S)$ and $\mathscr{B}_{\lambda}^{0}(S)$, their algebraic, categorical properties, applications and generalizations are established in [2, 3, 9, 11, 12, 13, 14, 15, 16, 17, 18, 19, 20, 21, 23, 26.

By $\omega_{\min }$ we denote the set $\omega$ with the binary operation

$$
x y=\min \{x, y\}, \quad \text { for } \quad x, y \in \omega .
$$

It is obvious that $\omega_{\min }$ is a semilattice.

We define a map $\mathfrak{f}: \boldsymbol{B}_{\omega}^{\mathscr{F}_{1}} \rightarrow \mathscr{B}_{\omega}\left(\omega_{\min }\right)$ by the formulae

$$
(i, j,\{k\}) \mathfrak{f}=(i+k, k, j+k) \quad \text { and } \quad(\mathbf{0}) \mathfrak{f}=\mathscr{O},
$$


for $i, j, k \in \omega$.

Proposition 2. The map $\mathfrak{f}: \boldsymbol{B}_{\omega}^{\mathscr{F}_{1}} \rightarrow \mathscr{B}_{\omega}\left(\omega_{\min }\right)$ is an isomorphic embedding.

Proof. It is obvious that the map $\mathfrak{f}$ defined by formulae (1) is bijective.

Fix arbitrary $\left(i_{1}, j_{1},\left\{k_{1}\right\}\right),\left(i_{2}, j_{2},\left\{k_{2}\right\}\right) \in \boldsymbol{B}_{\omega}^{\mathscr{F} 1}$. Then we have that

$$
\begin{aligned}
& \left(\left(i_{1}, j_{1},\left\{k_{1}\right\}\right) \cdot\left(i_{2}, j_{2},\left\{k_{2}\right\}\right)\right) \mathfrak{f}= \\
& =\left\{\begin{array}{cl}
\left(i_{1}-j_{1}+i_{2}, j_{2},\left(j_{1}-i_{2}+\left\{k_{1}\right\}\right) \cap\left\{k_{2}\right\}\right) \mathfrak{f}, & \text { if } j_{1}<i_{2} \text { and } j_{1}+k_{1}=i_{2}+k_{2} ; \\
(\mathbf{0}) \mathfrak{f}, & \text { if } j_{1}<i_{2} \text { and } j_{1}+k_{1} \neq i_{2}+k_{2} ; \\
\left(i_{1}, j_{2},\left\{k_{1}\right\} \cap\left\{k_{2}\right\}\right) \mathfrak{f}, & \text { if } j_{1}=i_{2} \text { and } k_{1}=k_{2} ; \\
(\mathbf{0}) \mathfrak{f}, & \text { if } j_{1}=i_{2} \text { and } k_{1} \neq k_{2} ; \\
\left(i_{1}, j_{1}-i_{2}+j_{2},\left\{k_{1}\right\} \cap\left(i_{2}-j_{1}+\left\{k_{2}\right\}\right)\right) \mathfrak{f}, & \text { if } j_{1}>i_{2} \text { and } j_{1}+k_{1}=i_{2}+k_{2} ; \\
(\mathbf{0}) \mathfrak{f}, & \text { if } j_{1}>i_{2} \text { and } j_{1}+k_{1} \neq i_{2}+k_{2}
\end{array}\right. \\
& =\left\{\begin{array}{cl}
\left(i_{1}-j_{1}+i_{2}, j_{2},\left\{k_{2}\right\}\right) \mathfrak{f}, & \text { if } j_{1}<i_{2} \text { and } j_{1}+k_{1}=i_{2}+k_{2} ; \\
\left(i_{1}, j_{2},\left\{k_{1}\right\}\right) \mathfrak{f}, & \text { if } j_{1}=i_{2} \text { and } k_{1}=k_{2} ; \\
\left(i_{1}, j_{1}-i_{2}+j_{2},\left\{k_{1}\right\}\right) \mathfrak{f}, & \text { if } j_{1}>i_{2} \text { and } j_{1}+k_{1}=i_{2}+k_{2} ; \\
(\mathbf{0}) \mathfrak{f}, & \text { if } j_{1}+k_{1} \neq i_{2}+k_{2}
\end{array}\right. \\
& =\left\{\begin{array}{cl}
\left(i_{1}-j_{1}+i_{2}+k_{2}, k_{2}, j_{2}+k_{2}\right), & \text { if } j_{1}<i_{2} \text { and } j_{1}+k_{1}=i_{2}+k_{2} ; \\
\left(i_{1}+k_{1}, k_{1}, j_{2}+k_{1}\right), & \text { if } j_{1}=i_{2} \text { and } k_{1}=k_{2} ; \\
\left(i_{1}+k_{1}, k_{1}, j_{1}-i_{2}+j_{2}+k_{1}\right), & \text { if } j_{1}>i_{2} \text { and } j_{1}+k_{1}=i_{2}+k_{2} ; \\
\mathscr{O}, & \text { if } j_{1}+k_{1} \neq i_{2}+k_{2}
\end{array}=\right. \\
& \begin{array}{cl}
\left(i_{1}+k_{1}, k_{2}, j_{2}+k_{2}\right), & \text { if } j_{1}<i_{2} \text { and } j_{1}+k_{1}=i_{2}+k_{2} ; \\
\left(i_{1}+k_{1}, k_{1}, j_{2}+k_{2}\right), & \text { if } j_{1}=i_{2} \text { and } k_{1}=k_{2} ; \\
\left(i_{1}+k_{1}, k_{1}, j_{2}+k_{2}\right), & \text { if } j_{1}>i_{2} \text { and } j_{1}+k_{1}=i_{2}+k_{2} ; \\
\mathscr{O}, & \text { if } j_{1}+k_{1} \neq i_{2}+k_{2},
\end{array}
\end{aligned}
$$

and

$$
\begin{aligned}
\left(\left(i_{1}, j_{1},\left\{k_{1}\right\}\right) \mathfrak{f} \cdot\right. & \left.\left(i_{2}, j_{2},\left\{k_{2}\right\}\right)\right) \mathfrak{f}=\left(i_{1}+k_{1}, k_{1}, j_{1}+k_{1}\right) \cdot\left(i_{2}+k_{2}, k_{2}, j_{2}+k_{2}\right)= \\
= & \left\{\begin{array}{cl}
\left(i_{1}+k_{1}, \min \left\{k_{1}, k_{2}\right\}, j_{2}+k_{2}\right), & \text { if } j_{1}+k_{1}=i_{2}+k_{2} ; \\
\mathscr{O}, & \text { if } j_{1}+k_{1} \neq i_{2}+k_{2}
\end{array}=\right. \\
= & \left\{\begin{array}{cl}
\left(i_{1}+k_{1}, k_{2}, j_{2}+k_{2}\right), & \text { if } k_{2}<k_{1} \text { and } j_{1}+k_{1}=i_{2}+k_{2} ; \\
\left(i_{1}+k_{1}, k_{1}, j_{2}+k_{2}\right), & \text { if } k_{2}=k_{1} \text { and } k_{1}=k_{2} ; \\
\left(i_{1}+k_{1}, k_{1}, j_{2}+k_{2}\right), & \text { if } k_{2}>k_{1} \text { and } j_{1}+k_{1}=i_{2}+k_{2} ; \\
\mathscr{O}, & \text { if } j_{1}+k_{1} \neq i_{2}+k_{2},
\end{array}\right. \\
= & \left\{\begin{array}{cl}
\left(i_{1}+k_{1}, k_{2}, j_{2}+k_{2}\right), & \text { if } j_{1}<i_{2} \text { and } j_{1}+k_{1}=i_{2}+k_{2} ; \\
\left(i_{1}+k_{1}, k_{1}, j_{2}+k_{2}\right), & \text { if } j_{1}=i_{2} \text { and } k_{1}=k_{2} ; \\
\left(i_{1}+k_{1}, k_{1}, j_{2}+k_{2}\right), & \text { if } j_{1}>i_{2} \text { and } j_{1}+k_{1}=i_{2}+k_{2} ; \\
\mathscr{O}, & \text { if } j_{1}+k_{1} \neq i_{2}+k_{2} .
\end{array}\right.
\end{aligned}
$$

Since $\mathbf{0}$ and $\mathscr{O}$ are the zeros of the semigroups $\boldsymbol{B}_{\omega}^{\mathscr{F}_{1}}$ and $\mathscr{B}_{\omega}\left(\omega_{\text {min }}\right)$, respectively, the above equalities imply that the map $\mathfrak{f}: \boldsymbol{B}_{\omega}^{\mathscr{F}_{1}} \rightarrow \mathscr{B}_{\omega}\left(\omega_{\text {min }}\right)$ is a homomorphism. This completes the proof of the proposition.

Next we define

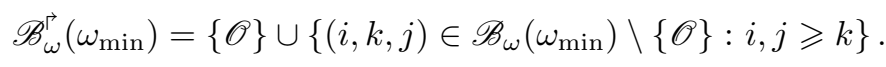


Simple verifications show that $\mathscr{B}_{\omega}^{\rightleftarrows}\left(\omega_{\text {min }}\right)$ is an inverse subsemigroup of $\mathscr{B}_{\omega}\left(\omega_{\min }\right)$.

Proposition 2 implies

Theorem 1. The semigroup $\boldsymbol{B}_{\omega}^{\mathscr{F}_{1}}$ is isomorphic to $\mathscr{B}_{\omega}^{\longmapsto}\left(\omega_{\min }\right)$ by the map $\mathfrak{f}$.

For any $i, j \in \omega$ we denote

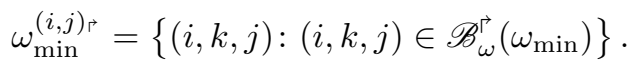

Proposition 3. Let $\tau$ be a shift-continuous $T_{1}$-topology on the semigroup $\mathscr{B}_{\omega}\left(\omega_{\min }\right)$.

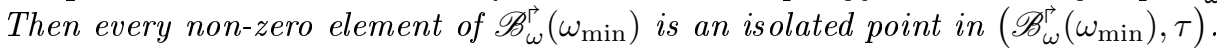

Proof. Fix arbitrary $i, j \in \omega$. Since $(i, 0, i) \cdot(i, 0, j) \cdot(j, 0, j)=(i, 0, j)$, the assumption of the proposition implies that for any open neighbourhood $W_{(i, 0, j)} \not \supset \mathscr{O}$ of $(i, 0, j)$ there exists its open neighbourhood $V_{(i, 0, j)}$ in the topological space $\left(\mathscr{B}_{\omega}^{\rightleftarrows}\left(\omega_{\min }\right), \tau\right)$ such that $(i, 0, i) \cdot V_{(i, 0, j)} \cdot(j, 0, j) \subseteq W_{(i, 0, j)}$. The definition of the semigroup operation on $\mathscr{B}_{\omega}\left(\omega_{\min }\right)$ implies that $V_{(i, 0, j)} \subseteq \omega_{\min }^{(i, j)_{\text {}}}$. Then the set $\omega_{\min }^{(i, j)_{\text {}}}$ is an open subset of $\left(\mathscr{B}_{\omega}\left(\omega_{\min }\right), \tau\right)$ because it is the full preimage of $V_{(i, 0, j)}$ under the mapping

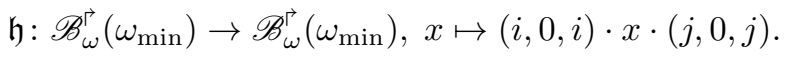

By Corollary 1 the set $\omega_{\min }^{(i, j)_{\rightleftarrows}}$ is finite, which implies the statement of the proposition.

Next we shall show that the semigroup $\mathscr{B}_{\omega}^{\longmapsto}\left(\omega_{\min }\right)$ admits a compact shift-continuous Hausdorff topology.

Example 1. A topology $\tau_{\mathrm{Ac}}$ on $\mathscr{B}_{\omega}^{\longmapsto}\left(\omega_{\min }\right)$ is defined as follows:

a) all nonzero elements of $\mathscr{B}_{\omega}^{\longmapsto}\left(\omega_{\text {min }}\right)$ are isolated points in $\left(\mathscr{B}_{\omega}^{\longmapsto}\left(\omega_{\min }\right), \tau_{\mathrm{Ac}}\right)$;

b) the family

$$
\begin{gathered}
\mathscr{B}_{\mathrm{Ac}}(\mathscr{O})=\left\{U_{\left(i_{1}, j_{1}\right), \ldots,\left(i_{n}, j_{n}\right)}=\mathscr{B}_{\omega}^{\longmapsto}\left(\omega_{\min }\right) \backslash\left(\omega_{\min }^{\left(i_{1}, j_{1}\right)_{\triangleright}} \cup \cdots \cup \omega_{\min }^{\left(i_{n}, j_{n}\right)_{\triangleright}}\right):\right. \\
\left.n, i_{1}, j_{1}, \ldots, i_{n}, j_{n} \in \omega\right\}
\end{gathered}
$$

is a base of the topology $\tau_{\mathrm{Ac}}$ at the point $\mathscr{O} \in \mathscr{B}_{\omega}^{\rightleftarrows}\left(\omega_{\min }\right)$.

Corollary 1 implies that the set $\omega_{\min }^{(i, j)_{\text {}}}$ is finite for any $i, j \in \omega$ which implies that $\left(\mathscr{B}_{\omega}\left(\omega_{\text {min }}\right), \tau_{\mathrm{Ac}}\right)$ is the one-point Alexandroff compatification of the discrete space $\mathscr{B}_{\omega}^{\longmapsto}\left(\omega_{\min }\right) \backslash\{\mathscr{O}\}$.

Proposition 4. $\left(\mathscr{B}_{\omega}\left(\omega_{\min }\right), \tau_{\mathrm{Ac}}\right)$ is a Hausdorff compact semitopological semigroup with continuous inversion.

Proof. It is obvious that the topology $\tau_{\mathrm{Ac}}$ is Hausdorff and compact.

Fix any $U_{\left(i_{1}, j_{1}\right), \ldots,\left(i_{n}, j_{n}\right)} \in \mathscr{B}_{\mathrm{Ac}}(\mathscr{O})$ and $(i, k, j),(l, m, p) \in \mathscr{B}_{\omega}\left(\omega_{\min }\right) \backslash\{\mathscr{O}\}$. Put

$$
\boldsymbol{K}=\left\{i, i_{1}, \ldots, i_{n}, j, j_{1}, \ldots, j_{n}\right\} \quad \text { and } \quad U_{\boldsymbol{K}}=\mathscr{B}_{\omega}^{\circledR}\left(\omega_{\min }\right) \backslash \bigcup_{x, y \in \boldsymbol{K}} \omega_{\min }^{(x, y)_{\rightleftarrows}} .
$$

Then we have that $U_{\mathbf{K}} \in \mathscr{B}_{\mathrm{Ac}}(\mathscr{O})$ and the following conditions hold

$$
\begin{aligned}
& U_{\boldsymbol{K}} \cdot\{(i, k, j)\} \subseteq U_{\left(i_{1}, j_{1}\right), \ldots,\left(i_{n}, j_{n}\right)}, \\
& \{(i, k, j)\} \cdot U_{\boldsymbol{K}} \subseteq U_{\left(i_{1}, j_{1}\right), \ldots,\left(i_{n}, j_{n}\right)},
\end{aligned}
$$




$$
\begin{gathered}
\{\mathscr{O}\} \cdot\{(i, k, j)\}=\{(i, k, j)\} \cdot\{\mathscr{O}\}=\{\mathscr{O}\} \subseteq U_{\left(i_{1}, j_{1}\right), \ldots,\left(i_{n}, j_{n}\right),} \\
\{\mathscr{O}\} \cdot U_{\left.\left(i_{1}, j_{1}\right), \ldots, i_{n}, j_{n}\right)}=U_{\left(i_{1}, j_{1}\right), \ldots,\left(i_{n}, j_{n}\right)} \cdot\{\mathscr{O}\}=\{\mathscr{O}\} \subseteq U_{\left(i_{1}, j_{1}\right), \ldots,\left(i_{n}, j_{n}\right)}, \\
\{(i, k, j)\} \cdot\{(l, m, p)\}=\{\mathscr{O}\} \subseteq U_{\left.\left(i_{1}, j_{1}\right), \ldots, i_{n}, j_{n}\right)}, \text { if } j \neq l, \\
\{(i, k, j)\} \cdot\{(l, m, p)\}=\{(i, \min \{k, m\}, p)\}, \quad \text { if } \quad j=l, \\
\left(U_{\left(j_{1}, i_{1}\right), \ldots,\left(j_{n}, i_{n}\right)}\right)^{-1} \subseteq U_{\left(i_{1}, j_{1}\right), \ldots,\left(i_{n}, j_{n}\right)} .
\end{gathered}
$$

Therefore, $\left(\mathscr{B}_{\omega}\left(\omega_{\min }\right), \tau_{\mathrm{Ac}}\right)$ is a semitopological inverse semigroup with continuous inversion.

We recall that a topological space $X$ is said to be

- perfectly normal if $X$ is normal and and every closed subset of $X$ is a $G_{\delta}$-set;

- scattered if $X$ does not contain a non-empty dense-in-itself subspace;

- hereditarily disconnected (or totally disconnected) if $X$ does not contain any connected subsets of cardinality larger than one;

- compact if each open cover of $X$ has a finite subcover;

- countably compact if each open countable cover of $X$ has a finite subcover;

- $H$-closed if $X$ is a closed subspace of every Hausdorff topological space in which it contained;

- infra H-closed provided that any continuous image of $X$ into any first countable Hausdorff space is closed (see [24]);

- feebly compact (or lightly compact) if each locally finite open cover of $X$ is finite [1];

- $d$-feebly compact (or DFCC) if every discrete family of open subsets in $X$ is finite (see [25]);

- pseudocompact if $X$ is Tychonoff and each continuous real-valued function on $X$ is bounded;

- $Y$-compact for some topological space $Y$, if $f(X)$ is compact for any continuous map $f: X \rightarrow Y$.

The relations between above defined compact-like spaces are presented at the diagram in $[22$.

Lemma 1. Every shift-continuous $T_{1}$-topology $\tau$ on the semigroup $\mathscr{B}_{\omega}^{\rightleftarrows}\left(\omega_{\min }\right)$ is regular.

Proof. By Proposition 3 every non-zero element of the semigroup $\mathscr{B}_{\omega}^{\rightleftarrows}\left(\omega_{\min }\right)$ is an isolated point in $\left(\mathscr{B}_{\omega}\left(\omega_{\min }\right), \tau\right)$. This implies that every open neighbourhood $V(\mathscr{O})$ of the zero $\mathscr{O}$ is a closed subset in $\left(\mathscr{B}_{\omega}^{\rightleftarrows}\left(\omega_{\min }\right), \tau\right)$, and hence the space $\left(\mathscr{B}_{\omega}^{\rightleftarrows}\left(\omega_{\min }\right), \tau\right)$ is regular.

Since in any countable $T_{1}$-space $X$ every open subset of $X$ is a $F_{\sigma}$-set, Theorem 1.5.17 from [7] and Lemma 1 imply the following corollary.

Corollary 2. Let $\tau$ be a shift-continuous $T_{1}$-topology on the semigroup $\mathscr{B}_{\omega}\left(\omega_{\min }\right)$. Then $\left(\mathscr{B}_{\omega}^{\dagger}\left(\omega_{\min }\right), \tau\right)$ is a perfectly normal, scattered, hereditarily disconnected space.

By $\mathfrak{D}(\omega)$ we denote the countable discrete space and by $\mathbb{R}$ the set of all real numbers with the usual topology.

Theorem 2. Let $\tau$ be a shift-continuous $T_{1}$-topology on the semigroup $\mathscr{B}_{\omega}^{\rightleftarrows}\left(\omega_{\min }\right)$. Then the following statements are equivalent: 

(i) $\left(\mathscr{B}_{\omega}\left(\omega_{\min }\right), \tau\right)$ is compact;
(ii) $\tau=\tau_{\mathrm{Ac}}$;
(iii) $\left(\mathscr{B}_{\omega}\left(\omega_{\min }\right), \tau\right)$ is $H$-closed;
(iv) $\left(\mathscr{B}_{\omega}^{i}\left(\omega_{\min }\right), \tau\right)$ is feebly compact;
(v) $\left(\mathscr{B}_{\omega}\left(\omega_{\min }\right), \tau\right)$ is infra $H$-closed;

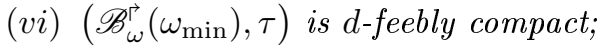
(vii) $\left(\mathscr{B}_{\omega}\left(\omega_{\min }\right), \tau\right)$ is pseudocompact;

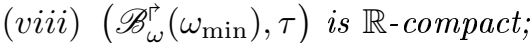
(ix) $\left(\mathscr{B}_{\omega}\left(\omega_{\min }\right), \tau\right)$ is $\mathfrak{D}(\omega)$-compact.

Proof. Implications $(i i) \Rightarrow(i) \Rightarrow($ iii $) \Rightarrow($ iv $) \Rightarrow(v) \Rightarrow(v i i i) \Rightarrow($ ix $)$ and $(i) \Rightarrow(v i i) \Rightarrow$ $(i v) \Rightarrow(v i)$ are trivial (see the diagram in [22]). Lemma1 1 implies implications $(v i) \Rightarrow(i v)$ and $($ iii $) \Rightarrow($ i) .

$(i x) \Rightarrow(i)$ Suppose to the contrary that there exists a shift-continuous $T_{1}$-topology $\tau$ on the semigroup $\mathscr{B}_{\omega}\left(\omega_{\text {min }}\right)$ such that $\left(\mathscr{B}_{\omega}^{\rightleftarrows}\left(\omega_{\text {min }}\right), \tau\right)$ is a $\mathfrak{D}(\omega)$-compact non-compact

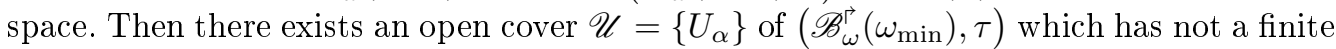
subcover. Let $U_{\alpha_{0}} \in \mathscr{U}$ such that $\mathscr{O} \in U_{\alpha_{0}}$. Since $\left(\mathscr{B}_{\omega}^{\rightleftarrows}\left(\omega_{\min }\right), \tau\right)$ is not compact the set

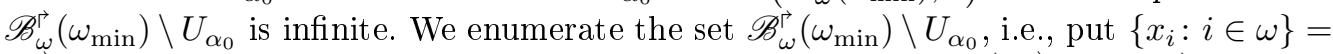
$\mathscr{B}_{\omega}^{\top}\left(\omega_{\min }\right) \backslash U_{\alpha_{0}}$. We identify $\mathfrak{D}(\omega)$ with $\omega$ and define a map $\mathfrak{f}:\left(\mathscr{B}_{\omega}\left(\omega_{\min }\right), \tau\right) \rightarrow \mathfrak{D}(\omega)$ in the following way

$$
(x) \mathfrak{f}= \begin{cases}0, & \text { if } x \in U_{\alpha_{0}} \\ i, & \text { if } x=x_{i}\end{cases}
$$

Proposition 3 implies that such defined map $\mathfrak{f}$ is continuous. Also, the image $\left(\mathscr{B}_{\omega}\left(\omega_{\min }\right)\right) \mathfrak{f}$ is not a compact subset of $\mathfrak{D}(\omega)$, which contradicts the assumption.

Theorem 2 implies

Corollary 3. Every shift-continuous $T_{1}$-topology $\mathfrak{D}(\omega)$-compact $\tau$ on the semigroup $\boldsymbol{B}_{\omega}^{\mathscr{F _ { 1 }}}$ is compact. Moreover the semigroup $\boldsymbol{B}_{\omega}^{\mathscr{F}_{1}}$ admits the unique compact shift-continuous $T_{1}$ topology.

Remark 1. By Proposition 4 of [10] the semigroup $\boldsymbol{B}_{\omega}^{\mathscr{F}_{1}}$ contains an isomorphic copy of the $\omega \times \omega$-matrix units. Then Theorem 5 from [16] implies that $\boldsymbol{B}_{\omega}^{\mathscr{F}_{1}}$ does not embed into a countably compact Hausdorff topological semigroup.

\section{ACKNOWLEDGEMENTS}

The author acknowledge her $\mathrm{PhD}$ Advisor Oleg Gutik and the referee for their comments and suggestions.

\section{REFERENCES}

1. R. W. Bagley, E. H. Connell, and J. D. McKnight, Jr., On properties characterizing pseudocompact spaces, Proc. Amer. Math. Soc. 9 (1958), no. 3, 500-506.

DOI: $10.1090 /$ S0002-9939-1958-0097043-2

2. S. Bardyla, An alternative look at the structure of graph inverse semigroups, Mat. Stud. 51 (2019), no. 1, 3-11. DOI: $10.15330 / \mathrm{ms} .51 .1 .3-11$ 
3. T. Berezovski, O. Gutik, and K. Pavlyk, Brandt extensions and primitive topological inverse semigroups, Int. J. Math. Math. Sci. 2010 (2010) Article ID 671401, 13 pages. DOI: $10.1155 / 2010 / 671401$

4. J. H. Carruth, J. A. Hildebrant and R. J. Koch, The theory of topological semigroups, Vol. I, Marcel Dekker, Inc., New York and Basel, 1983.

5. A. H. Clifford and G. B. Preston, The algebraic theory of semigroups, Vol. I., Amer. Math. Soc. Surveys 7, Providence, R.I., 1961.

6. A. H. Clifford and G. B. Preston, The algebraic theory of semigroups, Vol. II., Amer. Math. Soc. Surveys 7, Providence, R.I., 1967.

7. R. Engelking, General topology, 2nd ed., Heldermann, Berlin, 1989.

8. O. V. Gutik, On Howie semigroup, Mat. Metody Fiz.-Mekh. Polya 42 (1999), no. 4, 127-132 (in Ukrainian).

9. O. Gutik, On the group of automorphisms of the Brandt $\lambda^{0}$-extension of a monoid with zero, Proceedings of the 16th ITAT Conference Information Technologies - Applications and Theory (ITAT 2016), Tatranske Matliare, Slovakia, September 15-19, 2016. CEUR-WS, Bratislava, 2016, pp. 237-240.

10. O. Gutik and M. Mykhalenych, On some generalization of the bicyclic monoid, Visnyk Lviv. Univ. Ser. Mech.-Mat. 90 (2020) (to appear) (in Ukrainian).

11. O. V. Gutik, and K. P. Pavlyk, H-closed topological semigroups and topological Brandt $\lambda$ extensions, Mat. Metody Fiz.-Mekh. Polya 44 (2001), no. 3, 20-28, (in Ukrainian).

12. O. Gutik and K. Pavlyk, Topological Brandt $\lambda$-extensions of absolutely H-closed topological inverse semigroups, Visn. L'viv. Univ., Ser. Mekh.-Mat. 61 (2003), 98-105.

13. O. V. Gutik and K. P. Pavlyk, On Brandt $\lambda^{0}$-extensions of semigroups with zero, Mat. Metody Fiz.-Mekh. Polya 49 (2006), no. 3, 26-40.

14. O. V. Gutik and K. P. Pavlyk, Pseudocompact primitive topological inverse semigroups, Mat. Metody Fiz.-Mekh. Polya 56 (2013), no. 2, 7-19; reprinted version: J. Math. Sci. 203 (2014), no. 1, 1-15. DOI: $10.1007 /$ s10958-014-2087-5

15. O. V. Gutik and K. P. Pavlyk, On pseudocompact topological Brandt $\lambda^{0}$-extensions of semitopological monoids, Topol. Algebra Appl. 1 (2013), 60-79. DOI: 10.2478/taa-2013-0007

16. O. Gutik, K. Pavlyk, and A. Reiter, Topological semigroups of matrix units and countably compact Brandt $\lambda^{0}$-extensions, Mat. Stud. 32 (2009), no. 2, 115-131.

17. O. V. Gutik, K. P. Pavlyk, and A. R. Reiter, On topological Brandt semigroups, Mat. Metody Fiz.-Mekh. Polya 54 (2011), no. 2, 7-16 (in Ukrainian); English version in: J. Math. Sci. 184 (2012), no. 1, 1-11. DOI: 10.1007/s10958-012-0847-7

18. O. Gutik and O. Ravsky, On feebly compact inverse primitive (semi)topological semigroups, Mat. Stud. 44 (2015), no.1, 3-26.

19. O. V. Gutik and O. V. Ravsky, Pseudocompactness, products and Brandt $\lambda^{0}$-extensions of semitopological monoids, Mat. Metody Fiz.-Mekh. Polya 58 (2015), no. 2, 20-37; reprinted version: J. Math. Sci. 223 (2017), no. 1, 18-38. DOI: 10.1007/s10958-017-3335-2

20. O. Gutik and D. Repovš, On 0-simple countably compact topological inverse semigroups, Semigroup Forum 75 (2007), no. 2, 464-469. DOI: 10.1007/s00233-007-0706-x

21. O. Gutik and D. Repovš, On Brandt $\lambda^{0}$-extensions of monoids with zero, Semigroup Forum 80 (2010), no. 1, 8-32. DOI: $10.1007 / \mathrm{s} 00233-009-9191-8$

22. O. V. Gutik and O. Yu. Sobol, On feebly compact semitopological semilattice $\exp _{n} \lambda$, Mat. Metody Fiz.-Mekh. Polya 61 (2018), no. 3, 16-23; reprinted version: J. Math. Sc. 254 (2021), no. 1, 3-20. DOI: $10.1007 / \mathrm{s} 10958-021-05284-8$

23. O. Gutik and O. Sobol, Extensions of semigroups by symmetric inverse semigroups of a bounded finite rank, Visn. L'viv. Univ., Ser. Mekh.-Mat. 87 (2019), 5-36. 
24. D. W. Hajek and A. R. Todd, Compact spaces and infra H-closed spaces, Proc. Amer. Math. Soc. 48 (1975), no. 2, 479-482. DOI: 10.1090/S0002-9939-1975-0370499-3

25. M. Matveev, A survey of star covering properties, Topology Atlas preprint, April 15, 1998.

26. K. Pavlyk, Absolutely H-closed topological semigroups and Brandt $\lambda$-extensions, Applied Problems of Mechanics and Mathematics, 2 (2004), 61-68.

27. W. Ruppert, Compact Semitopological Semigroups: An Intrinsic Theory, Lect. Notes Math., 1079, Springer, Berlin, 1984. DOI: 10.1007/BFb0073675

28. V. V. Wagner, Generalized groups, Dokl. Akad. Nauk SSSR 84 (1952), 1119-1122 (in Russian).

Стаття: надійшла до редколегї 07.11.2019

доопрацвована 31.10.2020

прийнята до друку 17.11.2021

\title{
ПРО СЛАБКО КОМПАКТНІ ТОПОЛОГІї НА НАПІВГРУПІ $\boldsymbol{B}_{\omega}^{\mathscr{F}_{1}}$
}

\section{Олесандра ЛИСЕЦЬКА}

\author{
Лъвівсъжий начіоналъний університет імені Івана Франка, \\ вул. Університетсъка, 1, 79000, Лъвів \\ e-mail: o.yu.sobol@gmail.com
}

Вивчається напівгрупа Гутіка-Михаленича $\boldsymbol{B}_{\omega}^{\mathscr{F} 1}$ у випадку, коли сім'я $\mathscr{F}_{1}$ складається з порожньої множини та всіх одноточкових підмножин у $\omega$. Ми доводимо, що напівгрупа $\boldsymbol{B}_{\omega}^{\mathscr{F}}{ }^{1}$ ізоморфна піднапівгрупі $\mathscr{B}_{\omega}^{\longmapsto}\left(\omega_{\min }\right)$ $\omega$-розширенню Брандта напівг ратки $(\omega, \mathrm{min})$, описуємо всі трансляційно неперервні слабко компактні $T_{1}$-топології на напівгрупі $\mathscr{B}_{\omega}^{\rightleftarrows}\left(\omega_{\min }\right)$. Зокрема, доведено, що кожна трансляційно неперервна слабко компактна $T_{1}$ топологія $\tau$ на напівгрупі $\boldsymbol{B}_{\omega}^{\mathscr{F}_{1}} \in$ компактною, ба більше, у цьому випадку простір $\left(\boldsymbol{B}_{\omega}^{\mathscr{F}}, \tau\right)$ гомеоморфний одноточковій компактифікації Алєксандрова дискретного зліченного простору $\mathfrak{D}(\omega)$.

Ключові слова: напівтопологічна напівгрупа, слабко компактний, компактний, $\omega$-розширенню Брандта. 